\title{
Histomorphometry of umbilical cord and perinatal outcome in intrauterine growth restriction
}

\author{
Kotrannavar SS ${ }^{1}$, Dr Dhumale $\mathrm{HA}^{2}$, Shirol $\mathbf{V S}^{3}$, Humbarwadi $\mathbf{R S}^{4}$, Javali $\mathrm{SB}^{5}$, Desai $\mathrm{SP}^{6}$ \\ ${ }^{1 *}$ Dr Sangeeta S Kotrannavar, M Sc (Medical Anatomy) Research scholar, Department of Anatomy, ${ }^{2}$ Dr Hema A \\ Dhumale, M D, Professor, Department of Obstetrics \& Gynecology, ${ }^{3}$ Dr Veereshkumar S Shirol, M S, Professor, \\ Department of Anatomy, ${ }^{4}$ Dr Rajendra S Humbarwadi, M S, Professor, Department of Anatomy, ${ }^{5}$ Dr Shivalingappa B \\ Javali, M Sc (Stat), M Phil, Ph D, Associate Professor, Department of Community Medicine, ${ }^{6}$ Dr Suresh P Desai, M S, \\ Professor, Department of Anatomy. 1, 2, $3 \& 6$ are affiliated with J N Medical College, KLE University, Belagavi, \\ Karnataka, India. 4 \& 5 USM- KLE International Medical Programme, Belagavi, Karnataka, India.
}

Address for Correspondence: Dr Sangeeta S Kotrannavar, "Shiva Jyoti” H.No. 348, BUDA Scheme no. 51, Laxmi Tekadi, Ganeshpur road, behind Federal Bank, Belagavi - 9, Karnataka, India, E-mail address: sangeetakotrannavar@gmail.com

\begin{abstract}
Objective: To evaluate the histomorphometry of umbilical cord (UC) in intrauterine growth restricted (IUGR) newborns compared to appropriate for gestational age (AGA) newborns, and secondly to assess its impact on the intrapartum and perinatal outcome. Materials and Methods: A prospective observational study was conducted at Obstetrics and Gynecology unit of KLES Dr. Prabhakar Kore Hospital and Medical Research Centre, Belagavi. Study involved total 130 UCs of AGA and IUGR newborns. Tissues were fixed in formalin and paraffin embedded sections were examined. For each UC; UC cross sectional area (CSA), UC diameter and UC circumference parameters were measured under microscope with the help of digital image analyzer. Perinatal outcome like gestational age (GA) at delivery, birth weight, mode of delivery, sex of newborn, neonatal outcome and intrapartum complications were recorded. Independent $t$ test was used to compare means and chi-square test for categorical variables. Results: UC of IUGR newborns had significantly reduced UC area, diameter and circumference as compared to AGA newborns. IUGR newborns were associated with significant difference in GA at delivery, birth weight, neonatal intensive care unit admissions (NICU) and fetal distress. No significant difference was found in mode of delivery, sex of newborn and meconium stained liquor among AGA and IUGR groups. Conclusion: Assessment of CSAs of UC and its components can be used as early screening tool for fetal growth and it may provide useful information about pregnancy at risk and help in averting poor perinatal outcome.
\end{abstract}

Key words: Histomorphometry, IUGR, Perinatal outcome, Umbilical cord area, Umbilical cord circumference, Umbilical cord diameter.

\section{Introduction}

The umbilical cord (UC) connects the placental circulation with the fetal circulation and acts as nutritional channel between the mother and fetus. UC is composed of two umbilical arteries and one umbilical vein, which are surrounded by Wharton's jelly (WJ). Evaluation of gross as well as microscopic UC abnormalities, showed strong association with stillbirth, intrauterine growth restriction (IUGR) and meconium

Manuscript received: $25^{\text {th }}$ Oct 2015

Reviewed: $30^{\text {th }}$ Oct 2015

Author Corrected: $19^{\text {th }}$ Nov 2015

Accepted for Publication: $30^{\text {st }}$ Nov 2015 stained amniotic fluid [1]. The microscopic examination revealed that UCs of IUGR fetuses were significantly smaller and characterized by reduced umbilical CSA compared with those of healthy newborns [2]. Prevalence of lean UC was found to be higher in IUGR fetuses and correlated considerably with fetal distress in the ultrasonographic (USG) study [3, 4]. While the CSA of umbilical cord and vessels were, found to be higher in the mothers with gestational diabetes, fetal macrosomia [5].

Fetal growth is the result of integrated, coordinated interaction between maternal, fetal and placental 
factors, and any disintegration in this complex can lead to IUGR [6]. During the development, many fetuses adapt to malnutrition and it affects their structure and metabolism for a long term. These intra-uterine programmed changes may initiate adult disease [7]. IUGR is still not having effective therapeutic strategies. Basic research is very much required to understand the altered morphology of fetal tissue [6]. Since there is paucity of literature on UC morphology in IUGR for Indian population, hence we undertook this study to find out structural alteration in UC of IUGR. Objective of the study is first to evaluate the histomorphometry of UC in IUGR compared to appropriate for gestational age (AGA) newborn, and secondly to assess its impact on the intrapartum and perinatal outcome.

\section{Materials and Methods}

Materials: This prospective observational study was conducted at Obstetrics and Gynecology unit of KLES Dr. Prabhakar Kore Hospital and Medical Research Centre, Belagavi. The Institutional Human Ethical Committee approved the study. The study involved 130 umbilical cords; control or AGA group included 65 UC samples from women with uneventful pregnancy having AGA fetus, defined [8] as more than $10^{\text {th }}$ and less than $90^{\text {th }}$ percentile of the estimated fetal weight by USG (Mediscan sonocare software). Case group included 65 UC samples from confirmed IUGR pregnancies, (identified by USG using the same software) by taking abdominal circumference less than $10^{\text {th }}$ percentile or expected fetal weight less than $10^{\text {th }}$ percentile for the gestational age (GA) [9].

Inclusion criteria were singleton gestation, mother age between 18-35 years, GA between 37-40 weeks based on a reliable last menstrual period (LMP) or $1^{\text {st }}$ trimester USG. Pregnancy induced hypertension (PIH) is also one of the cause for IUGR so it is included in case group. Patients were excluded having twin pregnancy, pre-gestational diabetes, gestational diabetes, heart diseases, and unknown GA. Preterm delivery often results in low birth weight and UC cord have different size hence, excluded from the study. Women who met with all the inclusion criteria were informed about the study and invited to participate.
Informed and written consent was obtained from those who agreed to participate.

Patients were followed and observed till delivery of the babies, and the relevant personal data of mothers and newborns were recorded in predesigned proforma. For each subject, mother's age, gravidity, mode of delivery, gestational age at delivery, sex of newborn, and neonatal outcome (alive / NICU / stillbirth) were recorded. Newborn's birth weight was recorded using digital baby weighing machine immediately after the birth.

Methods: $5 \mathrm{~cm}$ of UC tissues were collected immediately after the delivery, $5 \mathrm{~cm}$ from the placental end and stored in $10 \%$ formalin. Formalin fixed, paraffin wax embedded sections were processed for light microscopy. $3 \mu \mathrm{m}$ thick series of transverse sections were taken and stained with hematoxylin and eosin (H\&E) and Masson's tricrome stain using standard histological techniques. Incomplete and tangential sections were excluded from the study. The sections were studied under Olympus microscope CX40 (Tokyo Japan) with digital camera DP21. The reliability of the instrument was analyzed by inter and intraobservers calibration by Kappa statistics. For each UC; UC CSA, UC diameter and UC circumference parameter was measured under $40 \mathrm{X}$ magnification. The microscopic view was projected on the computer screen. Area was measured using the polygonal area tool. UC diameter was measured using length tool and took two readings at right angles to each other and average was calculated. UC circumference was computed using formula $\mathrm{C}=\mathrm{D} \prod$, where $\mathrm{D}$ is diameter and $\prod$ is constant value $(22 / 7)$.

Statistical analysis: Before statistical analysis, the normality distribution was analyzed by KolmogorvSmimov test, and parameters met normal assumption $(p<0.05)$. The data were analyzed by parametric test like Independent $t$ test was performed for comparison between two groups for numerical data. Categorical data were analyzed by chi-square test using statistical software SPSS 21.0 version. The statistical significance was set at $5 \%$ level of significance $(\mathrm{p}<0.05)$.

\section{Results}

Table 1 shows a comparison of the clinical features of AGA and IUGR groups. The mean maternal age was similar in both groups. Primigravida women were more in IUGR group $n=34(52 \%)$ than AGA group $n=24(37 \%)$ but, no significant difference was observed. Incidence of pregnancy with anemia, PIH and oligohydramnios were observed significantly more in IUGR group. 
Table-1: Comparison of clinical features of AGA and IUGR groups.

\begin{tabular}{|c|c|c|c|c|c|}
\hline \multirow[t]{2}{*}{ Clinical features } & \multicolumn{2}{|c|}{ AGA group $n=65$} & \multicolumn{2}{|c|}{ IUGR group $n=65$} & \multirow[t]{2}{*}{ p value } \\
\hline & No. & $\%$ & No. & $\%$ & \\
\hline Maternal age, year [mean(SD)] & 24.6 & 3.39 & 23.4 & 3.13 & 0.0310 \\
\hline Consanguineous marriage & 6 & 9 & 8 & 12 & 0.5710 \\
\hline \multicolumn{6}{|l|}{ Gravidity } \\
\hline Primigravida & 24 & 37 & 34 & 52 & \multirow[t]{2}{*}{0.0780} \\
\hline Multigravida & 41 & 63 & 31 & 48 & \\
\hline $\begin{array}{l}\text { Pregnancy induced } \\
\text { hypertension }\end{array}$ & 0 & 0 & 13 & 20 & $0.0001^{*}$ \\
\hline Anemia & 14 & 22 & 33 & 51 & $0.0010^{*}$ \\
\hline Oligohydramnios & 1 & 2 & 14 & 22 & $0.0001 *$ \\
\hline Maternal Hypothyroidism & 1 & 2 & 2 & 3 & 0.5590 \\
\hline H/O Abortion & 7 & 11 & 6 & 9 & 0.7700 \\
\hline High risk pregnancy & 24 & 37 & 26 & 40 & 0.7180 \\
\hline
\end{tabular}

Umbilical cord characteristics in AGA and IUGR group's results are summarized in table 2. UC area was significantly lower in IUGR group $(39.56 \pm 13.92)$ than in AGA group $(54.40 \pm 16.59, \mathrm{p}=0.0001)$. The UC circumference $(20.05 \pm 4.01$ vs. $23.86 \pm 4.22)$ and UC diameter $(6.38 \pm 1.28$ vs. $7.60 \pm 1.34)$ was significantly smaller in IUGR group versus AGA group.

Table-2: Umbilical cord characteristics in AGA and IUGR newborns

\begin{tabular}{|l|l|l|l|l|}
\hline Variables & AGA newborns $\mathrm{n}=65$ & $\begin{array}{l}\text { IUGR newborns } \\
\mathrm{n}=65\end{array}$ & t value & p value \\
\hline UC CSA mm ${ }^{2}$ & $54.40 \pm 16.59$ & $39.56 \pm 13.92$ & 5.523 & $0.0001^{*}$ \\
\hline UC circumference mm & $23.86 \pm 4.22$ & $20.05 \pm 4.01$ & 5.268 & $0.0001^{*}$ \\
\hline UC Diameter mm & $7.60 \pm 1.34$ & $6.38 \pm 1.28$ & 5.292 & $0.0001^{*}$ \\
\hline *-significant, UC-umbilical cord, CSA-cross sectional area \\
\hline
\end{tabular}

Table 3 shows perinatal out come in AGA and IUGR newborns. A chi-square test of independence was performed to examine the relation of perinatal outcome of newborns between two groups. GA was significantly lower in IUGR group as compared to AGA group. Birth weight was also decreased in IUGR group (1.98 \pm 0.12$)$ as compared to AGA group (3.25 $\pm 0.50, \mathrm{p}=0.0001)$. Number of NICU admission $12(18 \%)$ and fetal distress $8(12 \%)$ were found significantly more in IUGR group compared to AGA group. No significant difference was found in mode of delivery $(\mathrm{p}=0.379)$, sex of newborn $(\mathrm{p}=0.219)$, meconium stained liquor $(\mathrm{p}=1.0)$ and stillbirth $(\mathrm{p}=1.0)$

\section{Discussion}

UC acts as conduit for nutrition between mother and fetus. The most common cause for IUGR is inadequate supply of nutrients and oxygen to fetus and if exposure of this insult continues for long-term, it will lead to permanent changes in their structure and metabolism, and initiates adult diseases [6, 7]. Placental insufficiency could be associated with alterations in the umbilical circulation, contributing further to the impairment of maternal-fetal exchanges.

We observed that there is significant reduction in UC area in IUGR neonates during our study, which is in agreement with previous studies either prenatal [3] or postnatal examination [2]. Raio et al. [3] reported higher prevalence of a lean umbilical cord in IUGR fetuses than in AGA fetuses. Similarly, in a microscopic morphometry Bruch et al. [2] observed reduction in UC area in IUGR compared with those of healthy newborns. The reduction in the UC area was mainly because of significant decrease in umbilical vein vessel area and its lumen area and WJ area. However, no significant difference was noted in umbilical artery vessel area and lumen area [2]. WJ is porous collagen rich tissue designed to provide mechanical support and structural protection for umbilical vessels to provide non-interrupted blood flow to fetus therefore fetal nourishment. WJ contains myofibroblast which are 
having contractile property and participate in the regulation of umbilical blood flow [10]. A positive correlation was found between fresh WJ weight and newborns weight [11]. In contrast, absence of WJ around the umbilical artery was associated with perinatal mortality [12].

Table- 3: Perinatal out come in AGA and IUGR newborns

\begin{tabular}{|c|c|c|c|c|}
\hline Variables & $\begin{array}{l}\text { AGA newborns } \\
\mathrm{n}=65\end{array}$ & $\begin{array}{l}\text { IUGR newborns } \\
n=65\end{array}$ & Test statistic & p value \\
\hline $\begin{array}{l}\text { Gestational age at delivery, weeks } \\
(\text { mean } \pm \text { SD) }\end{array}$ & $39.01 \pm 1.04$ & $37.95 \pm 1.13$ & $5.572 \dagger$ & $0.0010^{*}$ \\
\hline Birth weight, kg (mean \pm SD) & $3.25 \pm 0.50$ & $1.98 \pm 0.12$ & $19.708 \dagger$ & $0.0001 *$ \\
\hline \multicolumn{5}{|l|}{ Mode of delivery } \\
\hline Vaginal n (\%) & $38(58)$ & $32(49)$ & \multirow[b]{3}{*}{$1.938 \ddagger$} & \multirow[b]{3}{*}{0.3790} \\
\hline Instrumental n (\%) & $00(0)$ & $1(2)$ & & \\
\hline Cesarean $\mathrm{n}(\%)$ & $27(42)$ & $32(49)$ & & \\
\hline \multicolumn{5}{|l|}{ Sex of newborn } \\
\hline Male n $(\%)$ & $34(52)$ & $27(42)$ & \multirow[b]{2}{*}{$1.513 \ddagger$} & \multirow[b]{2}{*}{0.2190} \\
\hline Female $\mathrm{n}(\%)$ & $31(48)$ & $38(58)$ & & \\
\hline \multicolumn{5}{|l|}{ Neonatal outcome } \\
\hline Alive $\mathrm{n}(\%)$ & 64(98) & 64(98) & $0.000 \ddagger$ & 1.0000 \\
\hline NICU n (\%) & $1(2)$ & $12(18)$ & $10.342 \ddagger$ & $0.0010 *$ \\
\hline Stillbirth n (\%) & $1(2)$ & $1(2)$ & $0.000 \div$ & 1.0000 \\
\hline \multicolumn{5}{|l|}{ Intrapatum Complication } \\
\hline Meconium stained liquor $\mathrm{n}(\%)$ & $3(5)$ & $3(5)$ & $0.000 \ddagger$ & 1.0000 \\
\hline Fetal distress $\mathrm{n}(\%)$ & $2(3)$ & $8(12)$ & $3.900 \ddagger$ & $0.0480 *$ \\
\hline
\end{tabular}

The major growth-promoting factor during development before and after birth is insulin like growth factor-I (IGF-I), which has mitogenic and anabolic effects and correlated with fetal growth. Biochemically UC blood serum contains lower IGF, IGF binding protein-3, and leptin in IUGR neonates $[13,14]$. These factors could lead to hypodevelopment of UC structures along with overall growth of fetus. UC shows structural and functional changes mainly in WJ and umbilical vein as a result of external and internal factors. Reduction in WJ volume [15] and vasoconstriction in umbilical vein may lead to smaller size of UC $[2,16]$.

We found significant difference in UC diameter and circumference in IUGR neonate as compared with AGA newborns as was mentioned by Peyter et al. [16]. They also observed lower growth parameters, smooth muscle cross-sectional area and significant vasoconstriction in IUGR neonates that might be cause for reduced UC diameter. Vasoconstriction could explain the reduced umbilical venous blood flow velocity, which is well established in Doppler studies [17, 18]. Since umbilical vessels lack innervation, vasoactive substance like nitric oxide (NO) may play major role in regulation of blood flow, which was significantly reduced in umbilical vein of IUGR neonates supports this morphological changes [16]. NO participates in feto-placental vasculogenesis and angiogenesis through VEGF and angiopoietin signaling molecules. Vascular tone by NO is critically influenced by endothelial NO synthase (eNOS) which was substantially decreased in umbilical vessel endothelial cell. Inactivation of eNOS could explain the reduction in NOS-mediated vasodilation in vessel affected with fetal growth could explain the small size of UC [19].

The second important observation of this study is IUGR newborns are associated with significant difference in GA at delivery, birth weight, NICU admission and fetal distress. Studies [3, 4], had found similar perinatal outcome with lean UC. In prospective studies on UC area below $10^{\text {th }}$ percentile was strongly associated with low birth weight, low Apgar score, meconium stained liquor, increased risk for being small for gestational age and signs of fetal distress [3, 4]. In the present histomorphometric study, we did not find significant association with meconium stained liquor. This could 
be because of smaller sample size. Amniotic fluid supports fetal development and considered as one of the component for antenatal surveillance. We observed more number of pregnancies with less than $5 \mathrm{~cm}$ amniotic fluid volume was found to be in IUGR group. Oligohydramnios is risk factor for low birth weight and adverse perinatal complications [20]. UC area and mainly umbilical vein area below $10^{\text {th }}$ percentile had significantly association with adverse neonatal outcome and NICU admission [21]. IUGR fetuses with abnormal venous flow have worst perinatal outcome than abnormal umbilical arterial flow [22]. Hemodynamic factors also influence in structural remodeling of vessels. Continuous blood flow through the vessels regulates the vascular transwall pressure and maintains structural integrity of vessels [23].

\section{Conclusion}

Here we have demonstrated reduced UC area, diameter and circumference in IUGR compared to AGA full term neonates and showing association with perinatal complications. Any alteration in the size of UC may be used as indicator of fetal growth disorders. UC is link between developing fetus and placenta thus UC morphology may be reflecting the fetal status. Sepluveda et al. [24] suggest that detailed antenatal USG examination of UC morphology is needed and it should not be limit to number of vessels and umbilical artery Doppler flow. Assessment of CSAs of UC and its component can be used as early screening tool for fetal growth and it may provide useful information about pregnancy at risk and help in averting poor perinatal outcome. We suggest that in case of IUGR fetus and lean UC pre and postnatal examination of UC morphology should be integral part of fetal assessment for early management of neonatal complications. Limitation of our study is we have assessed CSAs between 37-40 weeks of gestation GA. Further prospective longitudinal histomorphological and clinical studies are required to explore relationship between UC and perinatal outcome.

\section{Funding: None}

Competing interests: None declared

Ethical clearance: The study was approved by the institutional human ethical committee.

\section{References}

1. Tantbirojn P, Saleemuddin A, Sirois K, Crum C, Boyd T, Tworoger S, et al. Gross abnormalities of the umbilical cord: related placental histology and clinical significance. Placenta. 2009 Dec;30(12):1083-8. DOI: 10.1016/j.placenta.2009.09.2005

2. Bruch JF, Sibony O, Benali K, Challier JC, Blot P, Nessmann C. Computerized microscope morphometry of umbilical vessels from pregnancies with intrauterine growth retardation and abnormal umbilical artery Doppler. Hum Pathol. 1997 Oct;28(10):1139-45. DOI: 10.1016/50046-8177(97)90251-3.

3. Raio L, Ghezzi F, Di Naro E, Duwe DG, Cromi A, Schneider H. Umbilical cord morphologic characteristics and umbilical artery doppler parameters in intrauterine growth-restricted fetuses. J Ultrasound Med. 2003 Dec;22(12):1341-7. PMID: 14682422

4. Raio L, Ghezzi F, Di Naro E, Franchi M, Maymon E, Mueller M, et al. Prenatal diagnosis of a lean umbilical cord: a simple marker for the fetus at risk of being small for gestational age at birth. Ultrasound Obstet Gynecol. 1999 Mar;13(3):176-80. DOI: 10.1046/j.14690705.1999.13030176.x

5. Cromi A, Ghezzi F, Di Naro E, Siesto G, Bergamini $\mathrm{V}$, Raio L. Large cross-sectional area of the umbilical cord as a predictor of fetal macrosomia. Ultrasound Obstet Gynecol. 2007 Nov;30(6):861-6. DOI: 10.1002/uog.5183

6. Sankaran S, Kyle PM. Aetiology and pathogenesis of IUGR. Best Pract Res Clin Obstet Gynaecol. 2009 Dec;23(6):765-77.

DOI:

10.1016/j.bpobgyn.2009.05.003

7. Barker DJ. In utero programming of chronic disease. Clin Sci. 1998 Aug;95(2):115-28. DOI: $10.1042 / \operatorname{cs} 0950115$

8. Somprasit C, Chanthasenanont A, Nuntakomon T. The change of umbilical cord components in intrauterine growth restriction comparative with normal growth fetuses by using sonographic measurement. J Med Assoc Thai. 2010 Dec;93(7):S15-S20. PMID: 21294395

9. Mandruzzato G, Antsaklis A, Botet F, Chervenak FA, Figueras F, Grunebaum A, et al. Intrauterine restriction (IUGR). J Perinat Med. 2008;36(4):277. DOI: 10.1515/JPM.2008.050 
10. Takechi K, Kuwabara Y, Mizuno M. Ultrastructural and immunohistochemical studies of Wharton's jelly umbilical cord cells. Placenta. 1993 MarApr;14(2):235-45. DOI: $\quad$ 10.1016/501434004(05)80264-4

11. Filiz AA, Rahime B, Keskin HL, Esra AK. Positive correlation between the quantity of Wharton's jelly in the umbilical cord and birth weight. Taiwanese J Obstet Gynecol. $2011 \quad$ Mar;50(1):33-6. DOI: 10.1016/j.tjog.2009.11.002

12. Labarrere C, Sebastiani M, Siminovich M, Torassa E, Althabe O. Absence of Wharton's jelly around the umbilical arteries: an unusual cause of perinatal mortality. Placenta. 1985 Nov-Dec;6(6):555-9. DOI: 10.1016/50143-4004(85)80010-2

13. Burkhardt T, Matter C, Lohmann C, Cai H, Lüscher $\mathrm{T}$, Zisch A, et al. Decreased umbilical artery compliance and IGF-I plasma levels in infants with intrauterine growth restriction-implications for fetal programming of hypertension. Placenta. 2009 Feb;30(2):136-41. DOI: 10.1016/j.placenta.2008.11.005

14. Christou H, Connors JM, Ziotopoulou M, Hatzidakis V, Papathanassoglou E, Ringer SA, et al. Cord blood leptin and insulin-like growth factor levels are independent predictors of fetal growth. J Clin Endocrinol \& Metab. 2001Feb;86(2):935-8. PMID: 11158070

15. Proctor L, Fitzgerald B, Whittle W, Mokhtari N, Lee E, Machin G, et al. Umbilical cord diameter percentile curves and their correlation to birth weight and placental pathology. Placenta. 2013 Jan;34(1):62-6. DOI: 10.1016/j.placenta.2012.10.015

16. Peyter A-C, Delhaes F, Baud D, Vial Y, Diaceri G, Menétrey $\mathrm{S}$, et al. Intrauterine growth restriction is associated with structural alterations in human umbilical cord and decreased nitric oxide-induced relaxation of umbilical vein. Placenta. 2014 Nov;35(11):891-9.

DOI:
17. Ferrazzi E, Rigano S, Bozzo M, Bellotti M, Giovannini N, Galan H, et al. Umbilical vein blood flow in growth-restricted fetuses. Ultrasound Obstet Gynecol. 2000 Oct;16(5):432-8. PMID: 11169327

18. Boito S, Struijk P, Ursem N, Stijnen T, Wladimiroff J. Umbilical venous volume flow in the normally developing and growth-restricted human fetus. Ultrasound Obstet Gynecol. 2002 Apr;19(4):344-9. DOI: $10.1046 /$ j.1469-0705.2002.0067.1x

19. Krause B, Carrasco-Wong I, Caniuguir A, Carvajal J, Farias M, Casanello P. Endothelial eNOS/arginase imbalance contributes to vascular dysfunction in IUGR umbilical and placental vessels. Placenta. 2013 Jan;34(1):20-8. DOI: 10.1016/j.placenta.2012.09.015

20. Manning FA, Hill LM, Platt LD. Qualitative amniotic fluid volume determination by ultrasound: antepartum detection of intrauterine growth retardation. Am J Obstet Gynecol. 1981 Feb;139(3):254-8. PMID: 7468691

21. Ghezzi F, Raio L, Günter Duwe D, Cromi A, Karousou E, Dürig P. Sonographic umbilical vessel morphometry and perinatal outcome of fetuses with a lean umbilical cord. J Clin Ultrasound. 2005 Jan;33(1):18-23. PMID: 15690443

22. Baschat A, Gembruch U, Reiss I, Gortner L, Weiner C, Harman C. Relationship between arterial and venous Doppler and perinatal outcome in fetal growth restriction. Ultrasound Obstet Gynecol. 2000 Oct;16(5):407-13. PMID: 11169323

23. Li W-C, Zhang H-M, Wang P-J, Xi G-M, Wang H$\mathrm{Q}$, Chen $\mathrm{Y}$, et al. Quantitative analysis of the microstructure of human umbilical vein for assessing feasibility as vessel substitute. Anna of Vasc Surg. 2008 May-Jun;22(3):417-24. DOI: 10.1016/j.avsg.2007.12.02

24. Sepulveda W. Time for a more detailed prenatal examination of the umbilical cord? Ultrasound Obstet Gynecol. 1999 Mar;13(3):157-60. PMID: 10204204.

\section{How to cite this article}

Kotrannavar SS, Dr Dhumale HA, Shirol VS, Humbarwadi RS, Javali SB, Desai SP. Histomorphometry of umbilical cord and perinatal outcome in intrauterine growth restriction. Int J Med Res Rev 2015;3(10):1251-1256. doi: 10.17511/ijmrr.2015.i10.227. 